Volume 3 Number 1 April 2006

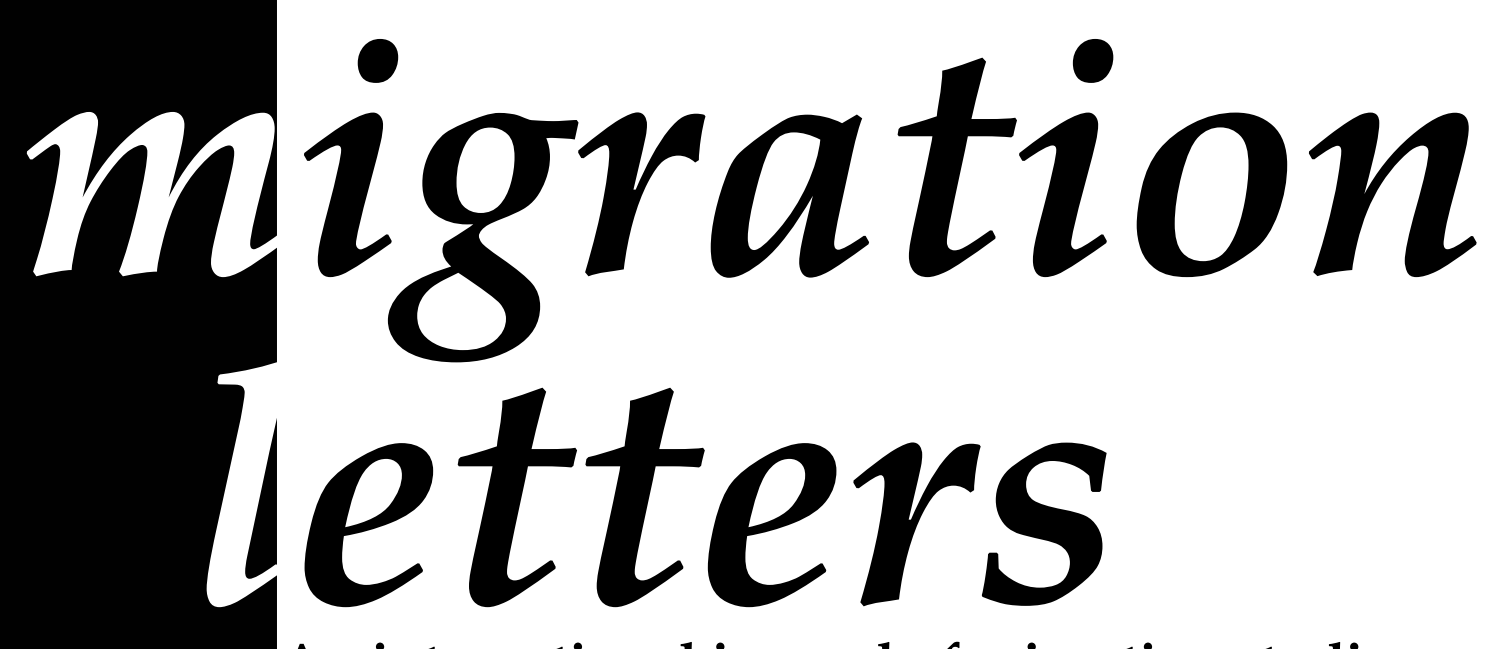

An international journal of migration studies 


\section{MIGRATION LETTERS}

An international journal of migration studies
VOLUME 3

NUMBER 1

April 2006

\section{Contents}

Migrants trafficking and individual strategies: the formation of dynamic channels in international migration

JOÃO PEIXOTO

Ethnic Residential Segregation and Assimilation in British Towns and Cities: a Comparison of those claiming Single and Dual Ethnic Identities

RON JOHNSTON, MICHAEL POULSEN AND JAMES FORREST

Ethnic conflict, wars and international migration of Turkmen: evidence from Iraq

IBRAHIM SIRKECI

Mental Health Workforce Collaboration and Partnership: Towards a response to World Health Assembly Resolution WHA 57.19

NICHOLAS G. PROCTER

International migration between Finland and the Baltic Sea Region

\section{ELLI HEIKKILÄ}

Haciendo de Tripas el Corazón/Plucking Up Courage: Migration, Family Internal Conflict, and Gender in Veronica's Story

\section{HILARY PARSONS DICK}

Where do they go? "A day without a Mexican," a perspective from south of the border

JEFFREY H. COHEN

Book reviews

Embracing the Infidel by Yaghmaian, Behzad 


\title{
Ethnic conflict, wars and international migration of Turkmen: evidence from Iraq
}

\author{
Ibrahim Sirkeci ${ }^{1}$
}

\begin{abstract}
Ethnic conflicts and wars have been a significant factor determining minority populations' outflow from Iraq. Turkmen as such minority have been subjected to oppression. Limited economic opportunities combined with the effects of wars imposed an environment of insecurity on Turkmen. This has further facilitated and promoted emigration as it offered "opportunity frameworks" for capable segments of this particular ethnic group. This paper presents findings from a survey conducted in Iraq in 2004 reaching 1040 Turkmen households. Systematic discrimination and ongoing internal and international conflicts and wars forced Turkmen as well as others to flee.
\end{abstract}

Keywords: environment of insecurity, opportunity frameworks, ethnic conflict, Turkmen, Iraq.

\section{Introduction}

Social scientists along with policy makers and practitioners have been discussing the root causes of migration, facilitating or impeding factors, and finally the ways in which human mobility can be managed, regularised, and controlled (Cornelius et al. 2004, Massey 1999, Massey et al. 1993). This endeavour is dated back to Ravenstein's (1889) laws of migration which has yet to receive any major challenge. As a multidimensional phenomenon, migration refutes any holistic theoretical framework. Instead, many partial models and approaches emerge. Among others, transnationalism ap-

1 European Business School London, Regent's College, London, NW1 4NS, United Kingdom. Email: sirkecii@ebs.regents.ac.uk. Author acknowledges the financial and logistic support of Global Strategy Institute (Ankara, Turkey) which made this research possible.

Migration Letters, Volume: 3, No: 1, pp. $31-42$.

April 2006 (ISSN: print: 1741-8984 \& online: 1741-8992) www.migrationletters.com 
INTERNATIONAL MIGRATION OF TURKMEN

pears to have gained an upper hand, I would argue, due to its broader view based on multifaceted and dynamic connections between different phases and components of international migration (Faist 2000). As a logical continuation of transnationalism approach, 'environment of insecurity and opportunity frameworks model' enables us to complete the picture by integrating the role of (ethnic) conflict to international migration, particularly in minority cases (Sirkeci 2006).

This model is based on a dual environment of insecurity, namely material and non-material: the former refers to actual war, clashes, physical abuse, torture, and economic deprivation, underdevelopment and so on while the latter is about intangible elements including legal or paralegal restrictions, psychological oppression, linguistic bans, and denial of ethnic identity. Under these circumstances, minority populations develop different strategies ranging from aligning with the oppressive forces or rebel forces to exit options including migration abroad (see Sirkeci 2003 and Icduygu et al. 1999). At the same time, direct exposure to the penalties of being a minority does not promise migration for most people but the existence of such penalties may facilitate migration of some who may not be under immediate threat but willing to migrate (Sirkeci 2005).

In Iraqi Turkmen case, the environment of insecurity is largely built upon ongoing wars starting from Iran-Iraq war and continuing through the 1990s and 2000s, but also including forced Arabisation and suppressive policies on minorities including Kurds and Turkmen (ICG 2003 and Ghai et al. 2003). Despite being an oil rich country, widespread poverty also needs to be mentioned. In this paper, using a recent survey data from Iraq, Turkmen migration is outlined and migration motives and patterns are linked to the EOI where possible.

Only a few variables from the survey are used here to support the environment of insecurity and opportunity frameworks argument. With this regard, economic and financial well-being of households, overlaps between the periods of emigration and heightened conflict are presented in contrast with motives of migration and type of entry in order 
to show the potential of this conceptual model for future research on international migration.

\section{Data and methods}

The data for the study is collected through a questionnaire survey conducted in 10 Iraqi cities and towns ${ }^{2}$ utilising, what I can call, a randomised non-probability sampling technique $^{3}$ to achieve as representative a sample as possible within given limitations. A four-module questionnaire was planned to be implemented by 40 interviewers in 1400 randomly selected Iraqi Turkmen households. Selection of locations with sizeable Turkmen populations was based on the past census results, literature and judgements of key informants from the Iraqi Turkmen community in Turkey. Three neighbourhoods were selected randomly in every town and city. 4 Then one centrally located street within each neighbourhood was selected. Interviews were held with 15 Turkmen households from each selected streets. Interviewers visited houses and/or flats beginning with the first residential building in the street until finding a Turkmen household and continuing the same procedure till completing 15 interviews. When the street accommodates too few households then interviewers proceeded to the next street until the required number of interviews is reached.

Four modules of the questionnaire were focusing on background characteristics of households and individuals along

2 Altunkopru, Baghdad, Besir, Dakuk, Erbil, Hanekin, Kerkuk, Musul, Suleymaniye, Taze, Telafer, Tuz, and Zeynelabidin were initially selected but due to security reasons it was not possible to proceed as planned. Hence, some areas had to be excluded reducing the final sample size to include 1040 households with 5986 individuals (2992 females and 2994 males).

${ }^{3}$ In the absence of any sample frame for the total population, from which to draw a probability sample, selection of towns were judgmental. Nevertheless a reasonable randomness was secured within each selected location. (See Neumann 2003 and Bryman 2001 for sampling).

${ }^{4}$ Except 10 neighbourhoods in Kerkuk, 4 in Erbil, 2 in Tuz, and 2 in Baghdad. 
INTERNATIONAL MIGRATION OF TURKMEN

along with their migration related experiences and perceptions. Module A asked about the background characteristics of key respondent in each household, while modules B and D were about household features including size of household, living conditions, quality of the living environment, cultural features such as religion and language, and values of household members. Module $C$ was on characteristics and experiences of migrants themselves.

Due to the nature of international migration, it was not possible to find current migrants to answer questions except in very few lucky cases in which migrants were visiting their families back home. Thus, in most cases, proxy respondents, usually the head of household, answered the questions. Return migrants, in most cases, answered the questions themselves. Among 5986 individuals, we identified 590 migrants (21\% were return migrants) and interviewed 454 of them in 371 households. 5

\section{Immediate environment: households}

At least one member had migrated abroad in 36\% of 1040 surveyed households (hereafter called "migrant households"). Migrant households are better off than the others. Monthly income for Iraqi Turkmen homes ranges from 99 USD to 500 USD. Migrant households bring in 312 USD (65 USD per head) per month at average compared to 268 USD (58 USD per head) of non-migrants (Figure 1).

GDP per capita in Iraq has been sharply declining until the recent war (2700 USD in 1999, 1600 USD in 20036). Then a recovery seems to be witnessed in 2005 and 2004: around 3400 USD and 2100 USD respectively ${ }^{7}$. These estimations do not allow us to reach conclusions but we can still see that level of income among Turkmen as recorded in this survey is

\footnotetext{
${ }^{5}$ We have collected information about and/or from only two migrants if more than two were identified. This was to avoid repetition of similar accounts and due to time and financial constraints. ${ }^{6}$ World Fact Book (2003 and 2005).

${ }^{7}$ Global Health Facts (2004).
} 


\section{SIRKECI}

much lower than the estimated averages in $2004 .{ }^{8}$ However, yet only $34 \%$ of non-migrants and $25 \%$ of migrants report they are not on sufficient finances while $27 \%$ of the former and $21 \%$ of the latter consider their homes financially worse than their neighbours. Distribution tables of income and perceptions of financial situation were skewed towards the lower ends.

Figure 1. Average monthly household income (US \$)

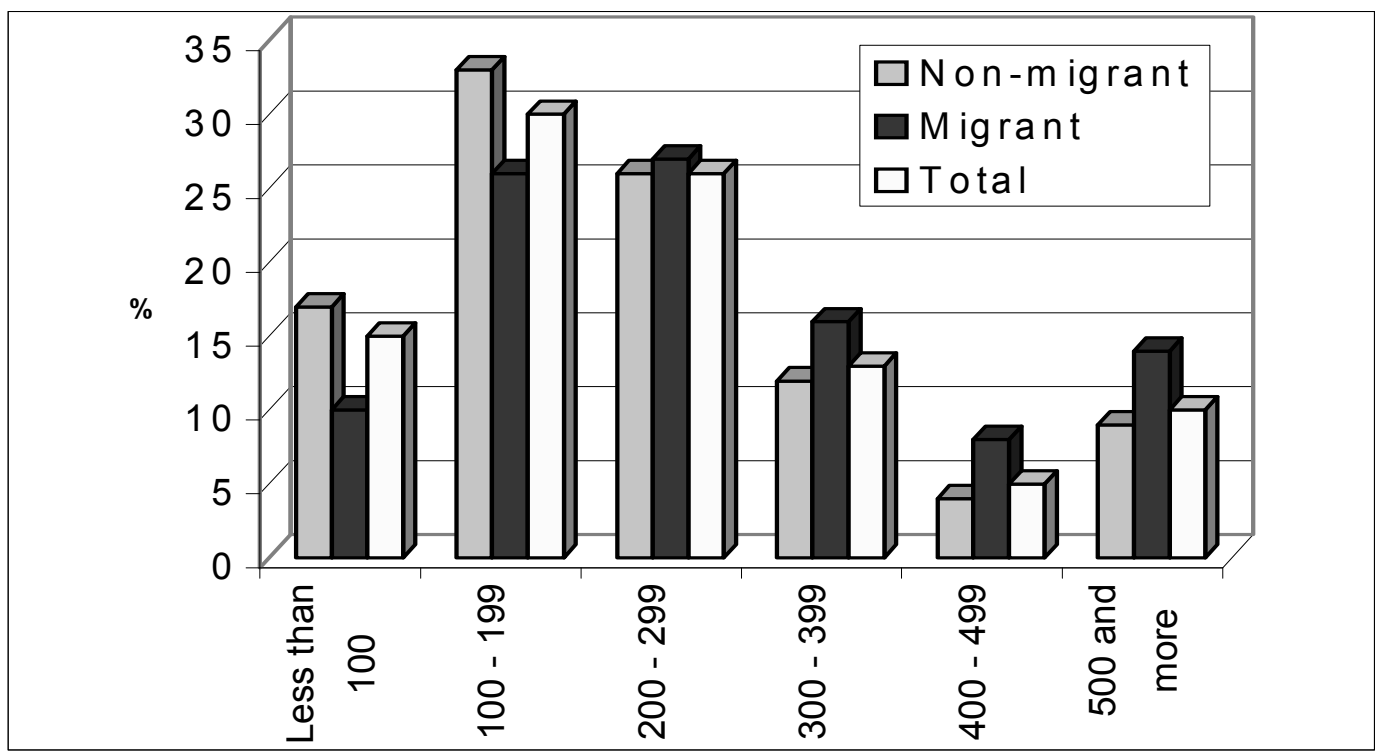

There are statistically significant differences in overall quality of homes as well as the level of satisfaction with current living conditions among the Turkmen: migrants' homes left behind are slightly better than others and their families feel more satisfied with their living conditions. 33\% of migrant households compared to $42 \%$ of non migrants scored five or less on a scale of one to ten, where ten being the highest satisfaction score.

A further important difference emerges regarding the number of essential household durables ${ }^{9}$ in possession along

8 The difficulty of acquiring income data in face to face interviews should be noted here. Respondents, although it may differ between cultures, often refrain to give exact earning figures.

9 These include fridge-freezers, washers, oven, cookers, computers, TVs, radios, car, farming trucks, and bicycles. 
INTERNATIONAL MIGRATION OF TURKMEN

with daily expenses. Households with more durables are more likely to have members abroad. Only $18 \%$ of migrant homes have 5 or less of durable items whereas this figure is $36 \%$ for others. This seems in line with the studies arguing that remittances are often used for upgrading buildings and buying durable goods and for daily expenses (Cohen 2005: 23). These representations may also be considered as supportive evidence for push-pull models of migration; and also giving further evidence for Hammar's (1995) right question of "why not many more migrations". Not the poorest or the richest but lower middle groups are likely to be migrants, which is evident in Turkmen case too. This is why we can argue that "people do not migrate because they must... rather, humans migrate because they can" (Cohen 2005: 19).

Iraqi Turkmen, as opposed to the common belief that Iraq is composed of homogeneous groups of Shiite, Sunni, Kurdish, and Turkmen groups, is a multi-religious group. Our analyses show that about 33\% is Shiite and 66\% Sunni while a small group of Christians is also available. ${ }^{10}$ Nevertheless, the data indicate no relationship between religious affiliation and migration in Turkmen case.

In brief, Turkmen seem to have resources enabling international migration considering their relative economic circumstances. High migration rates could be partly related to this. Non-material environment characterised by ongoing insecurity due to wars, ethnic tensions and conflicts Iraq witnessed in recent decades, I will argue, serves as opportunity frameworks to promote more emigration.

\section{Iraqi Turkmen emigration from Iraq}

International migration from Iraq seems indexed to the problems of multi-ethnic structure of the country's population contrasted with the mono-ethnic governing structure. There are hardly any comprehensive records and studies on Iraqi immigrant stock abroad. Intuitive figures range between 2 million and 4 million of Iraqis living abroad (Al-

10 Some sources reports that Turkmen population in Iraq is evenly divided between Sunnis and Shiites (ICG 2003: 7). 


\section{SIRKECI}

Rasheed 2005). Arab character of the state (referring to Arabisation) in Iraq forced many non-Arab minorities to flee since the 1920s. However massive out-flows seem emerged during the last 25 years starting from the war with Iran (Sirkeci 2005). The underlying motivations in all emigration flows from Iraq are political turmoils, ethnic character of the ruling groups, and surrounding wars. The data on Turkmen also suggest a similar motivation that is an environment of insecurity characterised by an overall socio-economic deprivation and ethnic suppression. Oil wealth never found a way towards average Iraqis welfare. It did not generate a stable economy and employment opportunities for the population (Al-Rasheed 2005: 317). Arabisation and systematic oppression of minorities, also including non-Baathist Arabs (Romano 2004), largely contributed to the EOI. Turkmen and others have emigrated whenever an escape route was open as well as whenever they were forced to do so.

Iraqi Turkmen, as representative as this data captures, have migrated to other countries in a pattern similar to general outflows from Iraq. Iraqi migrant populations including refugees and asylum seekers in industrialised countries is a little over 400000 according to available data for 1980-2002 period (Sirkeci 2005). ${ }^{11}$

Figure 2 displaying the annual distribution of Turkmen emigration displays peaks at heightened times of conflict in Iraq such 1991 for the Kuwait invasion and 1998 for Operation Desert Fox. As the research was carried out in 2004 summer, I did not have complete figures for the post-2003 war period. However, it is clear that migration from Iraq is highly responsive to the conflicts and Turkmen are no exception. In fact, emigration rate among Turkmen is rampant: $36 \%$ of the screened households in the survey were accommodating 590 migrant members (almost 10\% of total individuals). This is higher than rates in many emigration coun-

\footnotetext{
11 It should be noted here this figure is clearly dwarfed by claims of about 400000 Iraqis live in the UK alone (Times 2005: 43). One reason for this could be unknown volume of illegal migrants.
} 
INTERNATIONAL MIGRATION OF TURKMEN

tries. Nevertheless, higher emigration rates are not uncommon for minorities such as Kurds in Turkey (Sirkeci 2003).

Figure 2. Year of last migration abroad ( $\%$ of total)

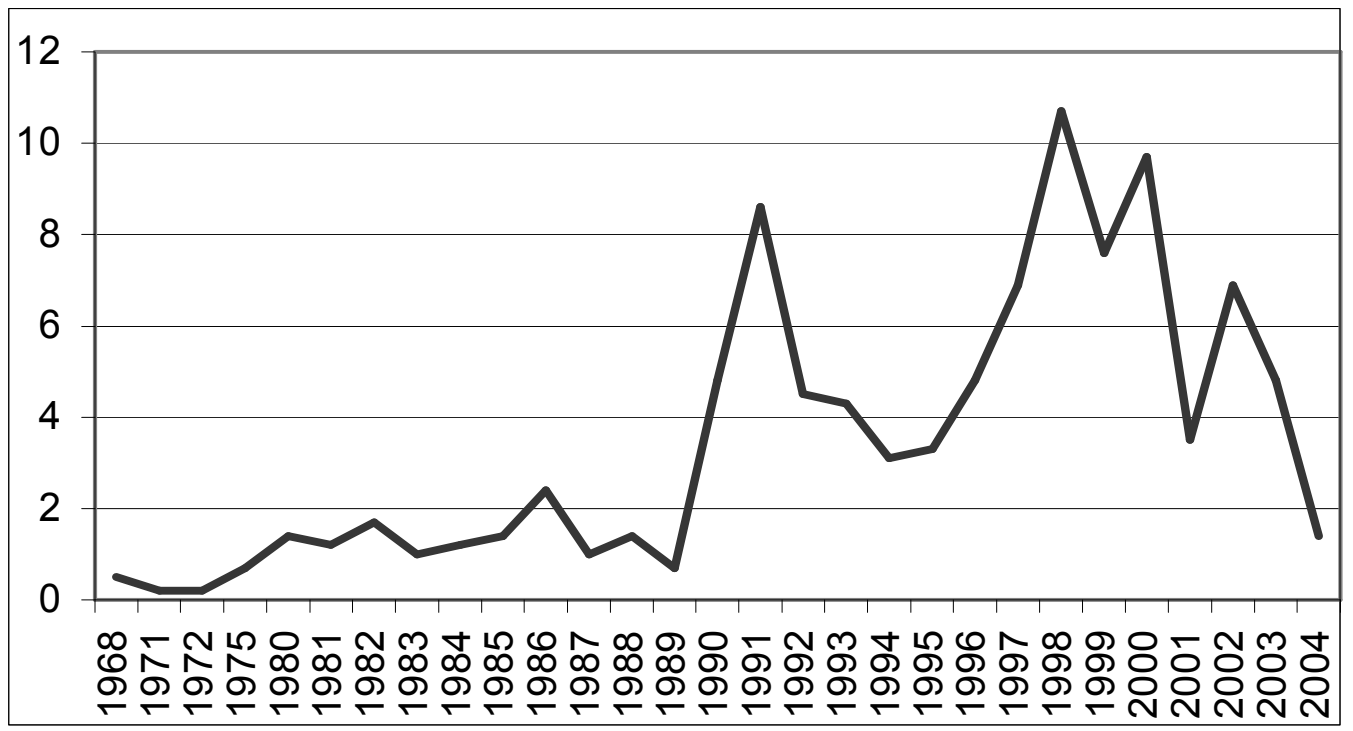

Figure 3 shows that almost two thirds of Turkmen migrants left Iraq due to political oppression, ethnic conflicts and wars contributing to the EOI. However, a sizeable segment, about two thirds, reported economic and political reasons together. Nevertheless, Iraqi Turkmen migration represents a forced migration case.

Figure 3. Motives of migration 12

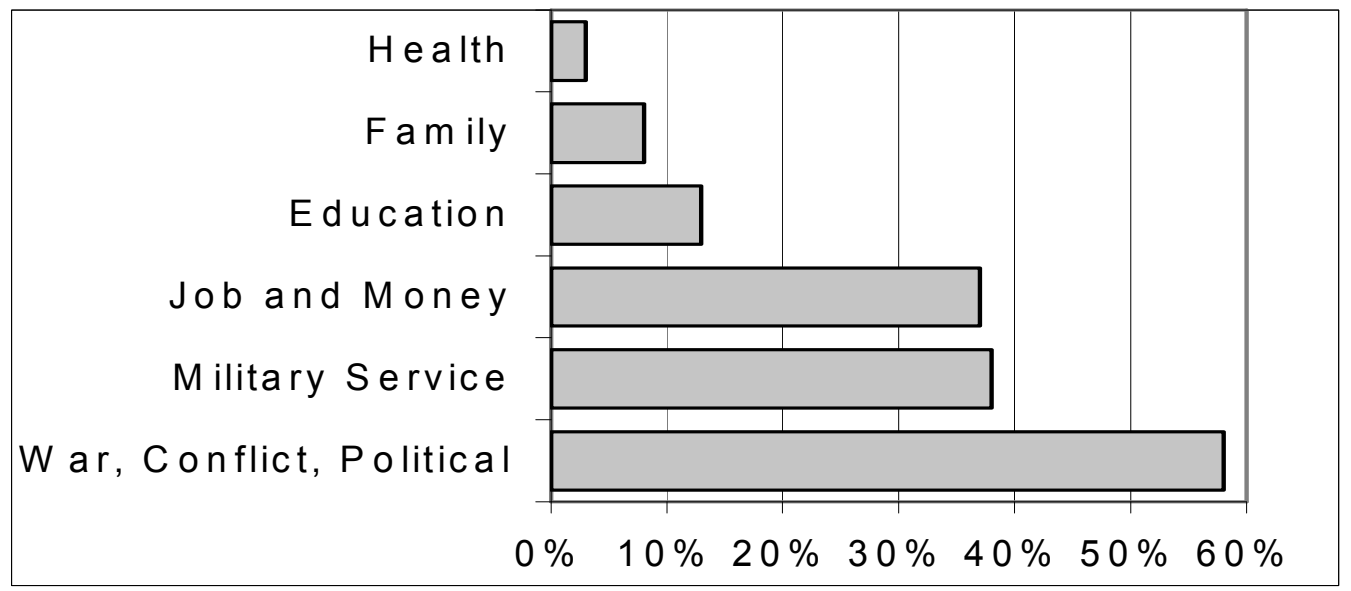

12 Please note proportions exceed $100 \%$ due to multiple responses. 


\section{SIRKECI}

Also among non-migrants who intend to move abroad within a year (about 25\%), the most important causes for their intention were economic betterment (35\%) and the trio of conflict, terror, and war (31\%). Despite the fact that political freedoms can easily be achieved when they fled Iraq, their economic expectations were reported unfulfilled. For example, only $6 \%$ of migrant Turkmen stated that they found better employment abroad than in Iraq.

In response to tightening admission rules in most destination countries with increasing efforts to control immigration (Cornelius et al. 2004, Zolberg 2005); Iraqi Turkmen have resorted to clandestine means to leave the country. Figure 4 is illustrating this: half of Turkmen emigrated without any entry clearance while another $17 \%$ entered the destination country on a tourist visa; both of which can be counted within clandestine migration.

\section{Figure 4. Type of entry clearance at the last migration}

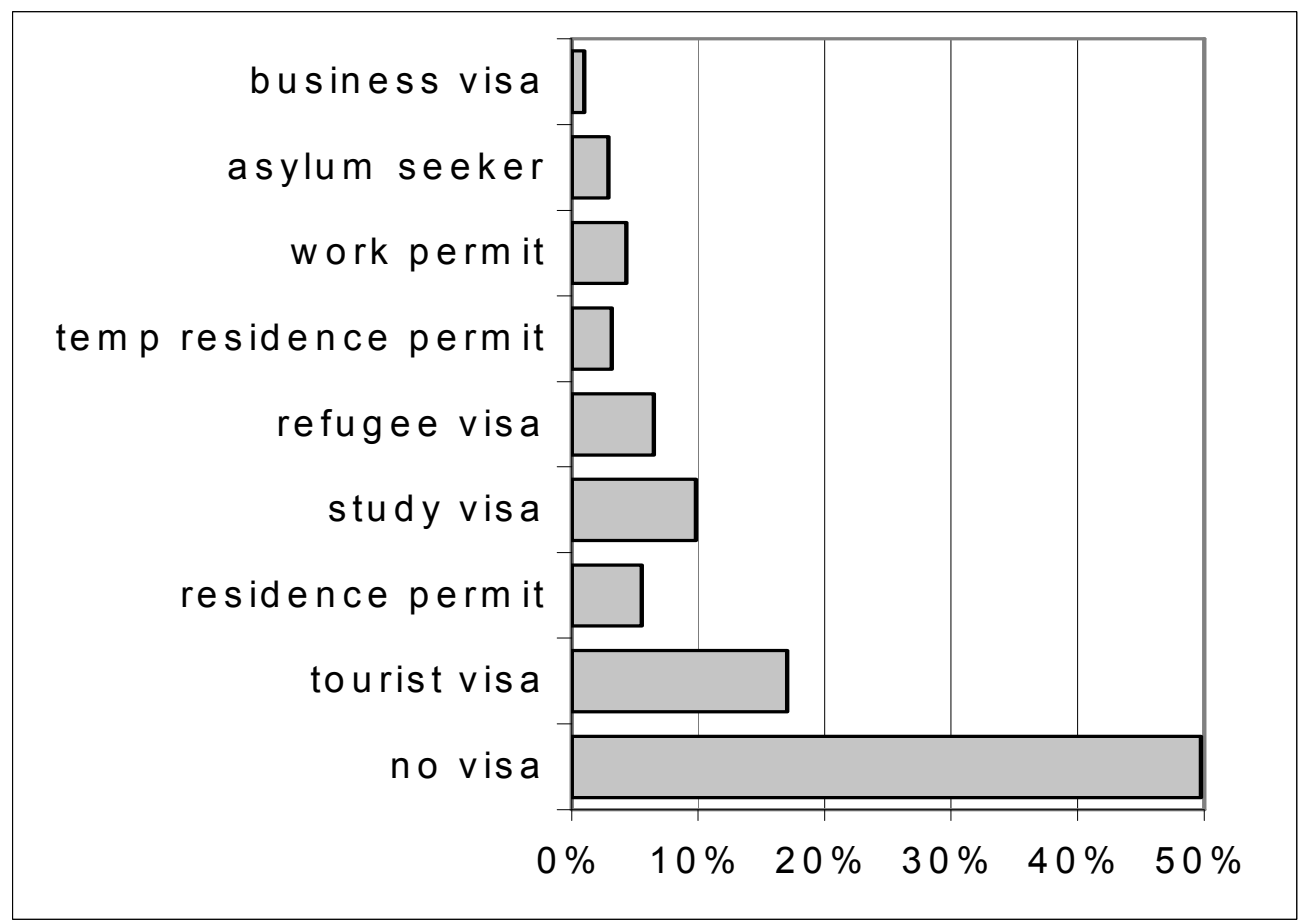

As mentioned above a high involvement of political causes, one should expect more asylum seeker flows or, in regard to the economic motivations, more labour migration would be expected. However, regulatory attempts of con- 
INTERNATIONAL MIGRATION OF TURKMEN

trolling agents seem only diverting the paths of migration flows; in essence it remains a complex human movement with multiple and/or mixed motivations finding appropriate ways to succeed.

\section{Conclusion}

I have described the environment of insecurity in reference to material and non-material conditions including economic, social, political, and cultural deprivation. A significant portion of Turkmen in Iraq opts for the exit strategy to cope with the overall environment of insecurity. Considering ongoing conflicts, wars, and oppression combined with socio-economic deprivation, many Turkmen, like some other Iraqis, feel the urge to move abroad as they choose the exit option as defined in the EOI model (Sirkeci 2005).

The analysis of Iraqi Turkmen's migration motives and patterns are supportive of my opportunity frameworks of migration argument. It is expected that when the conflict heightens people may want to opt out; therefore, the overlap between high volume of emigration and some heated conflict periods shown above is understandable. However, this is not true for everybody but for those who are capable of migrating abroad. Given the migrant households' relatively wealthy position compared to others, it is possible to argue that Turkmen, who have the resources and desire to migrate, could have benefited from the apparent environment of insecurity (which serves as an opportunity framework) in Iraq. Thus, he or she utilises the increased chances of being admitted to a better off immigration country easier than in any other time according to the opportunity frameworks argument. This is due to the fact that there are very few avenues left for "regular" or "legal" migration to the Western European countries (and other major destinations). Within very limited migration routes, clandestine migration followed by asylum seeking is often the only way for many migrants. Thus, migration goal (which can also be expressed as betterment of life in general terms) is achieved through that opportunity framework which increases the chances of admission on humanitarian and/or protection grounds. The claim here 


\section{SIRKECI}

is not the one that these people are "bogus asylum seekers", as frequently referred in the UK, but their migration needs due to a set of complex difficulties including different degrees of fear of persecution and economic deprivation could only be fulfilled when there is sharp conflict as such in Iraqi case. Besides, these borders between different types of migration have always been ambiguous. There have been times when these opportunity frameworks appeared within mass labour migration flows: even many would-be-refugees emigrated, then, as guest workers (Sirkeci 2003). For example, Turkish Kurds fled Turkey as guest workers for decades only until it was impossible; and then they turned to asylum seeking and later to clandestine migration (Sirkeci 2006).

Iraqi Turkmen and minorities under similar circumstances living in other countries provide rich opportunities for migration researchers in order to test their hypotheses and develop further conceptual models for a better understanding. They expose us the very complex nature of human movement under multiple influences involving interactions of different actors.

\section{References}

Al-Rasheed, Madawi (2005) "Iraqi Diaspora", in Gibney, M. and R. Hansen (eds.) Immigration and Asylum, ABC-Clio, Santa Barbara, California, US, pp.317-320.

Bryman, Alan (2001) Social Research Methods, Oxford University Publications, Oxford, UK.

Cohen, Jeffrey (2005) The Culture of Migration in Southern Mexico, University of Texas Press, Austin.

Cornelius, Wayne, T. Takeyuki, P.L. Martin, and J. F. Hollifield (eds.) (2004) Controlling Immigration, A global perspective, Second edition, Stanford University Press, Stanford, California, US.

Faist, Thomas (2000) International Migration and Transnational Social Spaces, Oxford University Press, Oxford.

Ghai, Y., M. Lattimer and L. Said (eds.) (2003) Building Democracy in Iraq, Minority Rights Group International. 
INTERNATIONAL MIGRATION OF TURKMEN

Global Health Facts (2004) "GDP per capita", available online at http:/ / www.globalhealthfacts.org/topic_pf.jsp?i=40\&srt=2.

Hammar, Tomas (1995) “Why have not many more emigrants left the South?" in van der Erf, R. and L. Heering (eds.) Causes of International Migration, Office for Official Publications of the European Communities, Luxembourg.

Hurst, Greg (2005) "Voting in Glasgow for a Baghdad MP", the Times, January 14, 2005, London, UK, p.43.

Icduygu, A., D. Romano, and I. Sirkeci (1999) "The ethnic question in an environment of insecurity: the Kurds in Turkey", Ethnic and Racial Studies, Vol.22, No.6, pp. 991-1010.

ICG (International Crisis Group) (2003) War in Iraq: What's Next for the Kurds?, Amman Brussels, 19 March.

Massey, Douglas (1999) "International Migration at the Dawn of the Twenty-First Century: The Role of the State", Population and Development Review, Vol.25, pp.303-323.

Massey, Douglas et al. (1993) "Theories of international migration: a review and appraisal", Population and Development Review, Vol.19, No.3, pp.431-466.

Neumann, W. Lawrence (2003) Social Research Methods, Allyn and Bacon, New York, US.

Ravenstein, E. G. (1889) "The laws of migration", Journal of the Royal Statistical Society, Vol.52, No.2, pp.241-301.

Romano, David (2004) "Whose House is this Anyway? IDP and Refugee Return in Post-Saddam Iraq", paper presented at the Fifth Mediterranean Social and Political Research Meeting, Florence \& Montecatini Terme, 24-28 March 2004, the Robert Schuman Centre for Advanced Studies, the EUI.

Sirkeci, Ibrahim (2006) Environment of Insecurity, Edwin Mellen Press, Ceredigion, UK. (Forthcoming).

. (2005) "War in Iraq: environment of insecurity and international migration", International Migration, Vol.43, No.4, pp.197-214.

. (2003) Migration, Ethnicity, Conflict: environment of insecurity and Turkish Kurdish international migration, unpublished $\mathrm{PhD}$ thesis, University of Sheffield, UK.

World Fact Book (2003 and 2005) "Iraq", CIA, available: http:// www. cia.gov / cia/publications/factbook/geos/iz.html

Zolberg, Aristide (2005) "Visitors, immigrants, and U.S. border security after September 11, 2001", in: Gibney, M. and R. Hansen (eds.) Immigration and Asylum From 1900 to the Present, ABC-CLIO, Santa Barbara, pp.669-677. 